\title{
Spread of nanostructure of S-Layer among the bacteria isolated from Skin
}

\author{
Shila Jalalpoor \\ Lecture of Microbiology, Shahreza Branch, Islamic Azad University, and Membership of Young Researchers Club, Iran. \\ shilla.jalalpoor@yahoo.com, jalalpour@iaush.ac.ir
}

\begin{abstract}
An S-layer (surface layer) is a part of the cell envelope commonly found in bacteria, as well as among archaea. It consists of a monomolecular layer composed of identical proteins or glycoproteins. As for many bacteria, the S-layer represents the outermost interaction zone with their respective environment, its functions are very diverse and vary from species to species; subject of this study was to find out the prevalence of Nanostructure of Surface layer among the Bacillus cereus isolated from the skin of clinical staff. Relevant information to Surface Layer was extracted from articles that listed in Pubmed, Elsivier Science, and Yahoo from 1995 to 2010 years. The research was performed with laboratory method during 2005-2007 years in Azzahra Hospital and Esfahan University. Bacterial identification was performed with standard bacteriological methods and selective culture medium was applied in preparation of samples. Bacterial samples were cultured in TSA, for 16 hour, in aerobic condition then separated the surface proteins to run electrophoresis with molecular weight marker. S-Layer in Bacillus cereus has 97KD molecular weight. Among the 13 Bacillus cereus strains isolated from skin of staff, $11(84.60 \%)$ showed positive for S-layer. S-layers in pathogenic bacteria offer protection against bacteriophages and phagocytosis, resistance against low $\mathrm{pH}$, adhesion, stabilisation of the membrane and provide adhesion sites for exoproteins due to more pathogenesis, infection resistant and antibiotic resistant to bacteria. Result of this study shows the prevalence of S-layer in pathogen bacteria and as important to determine S-layer producer strains in laboratory.
\end{abstract}

Keywords: Surface Layer, Pathogen Bacteria, Bacillus cereus

Introduction
All of the various surface components of a bacterial cell are important in its ecology since they mediate the contact of the bacterium with its environment. They are the only "senses" that a bacterium possesses result from its immediate contact with its environment. It must use its surface components to assess the environment and respond in a way that supports its own existence and survival in that environment. The surface properties of a bacterium are determined by the exact molecular composition of its membrane and cell envelope, including capsules, glycocalyx, S-layers, peptidoglycan and LPS, and the other surface structures, such as flagella and pili or fimbriae.

Nosocomial infections (NIs) remain a major global concern. Overall, national prevalence rates have been described as ranging between 3.5 and $9.9 \%$. They lead to additional days of treatment, increase the risk of death, and increase treatment costs. Staff hands have important role in NIs (Kamp \& Kramer, 2004).

Microorganisms are present in great numbers in moist, organic environments, but some also can persist under dry conditions. Environmental source or means of transmission of infectious agents, the presence of the pathogen does not establish its causal role; its transmission from source to host could be through indirect means, e.g., via hand transferal (Sehulster \& Raymond, 2003). The surface would be considered one of a number of potential reservoirs for the pathogen. Although microbiologically contaminated surfaces can serve as reservoirs of potential pathogens, these surfaces generally are not directly associated with transmission of infections to either staff or patients. The transferal of microorganisms from environmental surfaces to patients is largely via hand contact with the surface. The most important and frequent mode of transmission of nosocomial infections, is divided into two subgroups: direct-contact transmission and indirect-contact transmission (Sehulster \& Raymond, 2003).

Bacillus cereus bacteria strains are common in the environment and can be found in soil, dust, air, water, and on decaying. It has been regarded as a relatively nonpathogenic opportunist commonly associated with enterotoxin mediated diarrheal food poisoning. This organism has been increasingly isolated from serious nongastrointestinal infections including endocarditis, wound infection, osteomyelitis, oral cavity associated with infected root canals, periodontal pockets, bovine mastitis, severe systemic, pyogenic infections, gangrene, septic meningitis, cellulitis, panophyhalmitis, lung abscesses, infant death, and endocarditis and now B.cereus regarded one of nosocomial infections bacteria (Vander Zwet et al., 2000; Hilliard et al., 2003; Washington et al., 2006).

Survival spore forming bacteria on hands and surfaces in vegetative cells of can survive for at least $24 \mathrm{~h}$ on inanimate surfaces, and spores survive for up to 5 months (Kamp \& Kramer, 2004).

Surface structures are an important structural component of prokaryotic organisms and essential for many aspects of their life (Jalalpoor et al., 2007). B.cereus produces several potential virulence factors in addition to the toxins associated with gastrointestinal infections, and these factors are thought to play a role in 
non-gastrointestinal infections. These virulence factors include three hemolysins, three phospholipases, three different beta lactamases, extracellular collagenases, membrane-bound proteases, and S-layer (Jalalpoor et al., 2007; Washington et al., 2006).

Nosocomial outbreaks of Bacillus infections attributed to common-source spread from contaminated reservoirs in an environment. These sources have included contaminated hemodialyzers, bronchoscopes, Ommaya reservoirs, manual ventilation balloons, multiple-unit injectables, and contaminated diapers, gloves, and surgical bandages (Washington et al., 2006; Jalalpoor et al., 2007).

In medical situations, the surface components of bacterial cells are major determinants of virulence for many pathogens. The surface properties of a bacterium are determined by the exact molecular composition of its membrane and cell envelope, including capsules, glycocalyx, S-layer, peptidoglycan, LPS, and the other surface structures, such as flagella and pili or fimbriae (Todor 2005; Jalalpoor et al., 2007).

Over the past 3 decades of research, it has become apparent that one of the most common surface structures on bacteria are monomolecular crystalline arrays of proteinaceous subunits termed surface layer or S-layer. S-layer attached to the outermost portion of their cell wall. It consists of a single molecular layer composed of identical proteins or glycoproteins and in electron micrographs, has a pattern resembling floor tiles (Sara \& Sleytr, 2000; Mesnage et al., 2001; Sara, 2001; Messner et al., 2008). Because S-layer lattices possess pores identical in size and morphology in the 2 to $8 \mathrm{~nm}$ range, occupying up to $70 \%$ of the surface area they work as precise molecular sieves, providing sharp cutoff levels for the bacterial cells.

The repetitive features of S-layers have led to their use as immobilization matrices for binding of monolayers of functional molecules e.g., enzymes, antibodies, antibiotics and immunogens in a geometrically welldefined way. S-layers can contribute to virulence when they are present as a structural component of the cell envelope of pathogens (Sara \& Sleytr, 2000; Schaffer \& Messner, 2001; Eichler, 2003; Masahiro et al., 2003; Schaffer \& Paul, 2005).

Spread of S-layer producer B.cereus strains in staff hands is due to increase of antibiotic resistant NIs. The prevalence of increased of antibiotic resistance nosocomial infection in Iran and role of staff hand in nosocomial infection and transfer bacteria in hospital, the aims of this search was to survey the frequency of Bacillus cereus strains in staff hands and spread of Nanostructure of S-Layer among the Bacillus cereus strains isolated from skin of staff.

Materials and methods

Sampling

A total 80 bacterial strains from staff hands were isolated of Azzahra-hospital during of 2005-2007 years.

\section{Staff hand samples}

All samples were randomly collected from staff hand in Blood Agar (Merck) via Fingerprint Technique (Sehulster \& Raymond, 2003; Jalalpoor et al., 2007; Jalalpoor et al., 2009).

\section{Bacterial strains}

Specimen grown on sheep blood were incubated at $37{ }^{\circ} \mathrm{C}$ under aerobic conditions. Gram stains from blood cultures results in Gram-positive bacilli; intracellular and cell-free spores do not stain by the Gram technique but may be visualized with the malachite green stain for the spores that can appear green. On SBA, colonies of $B$.cereus usually large, with a matte or granular texture, and most strains are beta hemolytic. The strains were identified based on colony morphology, Gram stain reaction, spore formation, and biochemical tests with the BioMerieux database system (Kotiranta et al., 1998; Kotiranta et al., 1999; Washington et al., 2006).

\section{Detection of S-layer}

For the examination of surface proteins, $16 \mathrm{~h}$ old bacterial cells cultured on TSA enriched with $0.6 \%$ yeast extract and were collected from the agar plates, washed once in phosphate buffered saline (PBS) (pH 7.4), and suspended in the same buffer. The cell suspensions were adjusted to standard optic density; optical density of 0.6 $(450 \mathrm{~nm})$. Equal volumes $(4 \mathrm{ml})$ of the cell suspensions were centrifuged $(3,0003 \mathrm{~g}, 6 \mathrm{~min})$. The pellets were resuspended in $500 \mathrm{ml}$ of $1 \%$ sodium dodecyl sulfate (SDS)-Tris- $\mathrm{HCl}(\mathrm{pH} 8)$ and shaken for $30 \mathrm{~min}$ at RT. After centrifugation, the supernatants were boiled for $5 \mathrm{~min}$ in sample buffer $(60 \mathrm{mM}$ Tris- $\mathrm{HCl}, 1 \%$ SDS, $10 \%$ glycerol, $1 \%$ mercaptoethanol, and $0.0005 \%$ bromophenol blue) (Kotiranta et al., 1998; Kotiranta et al., 1999) and analyzed by SDS-10\% polyacrylamide gel (PAGE) electrophoresis that shown in Fig.1 (Sambrook \& Russell, 2001).

Fig. 1. SDS PAGE of surface proteins in B.cereus strains,

Lane 1: Myosin 206 kDa-Betagalactosidase $117 \mathrm{kDa}$ - BSA

$80 \mathrm{kDa}$ - Ovalbumin, $40 \mathrm{kDa}$ and Lane 2- 12 : B.cereus strains isolated from staff hand

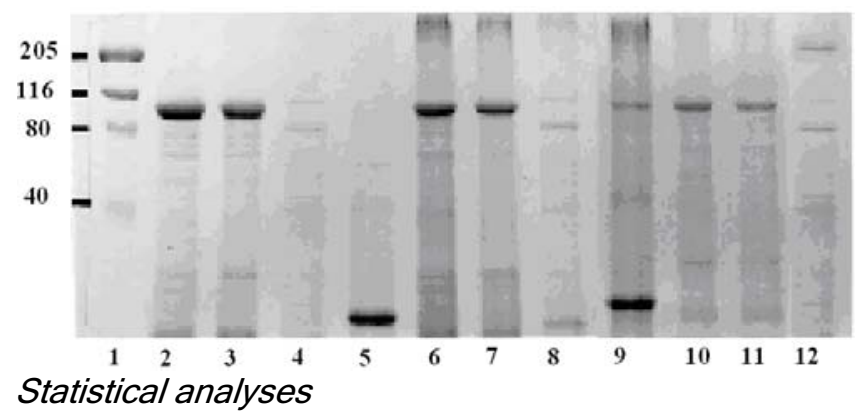

All the statistical analyses carried out using SPSS version 14. Chi-square and fisher test used for determination of significance of association. The $p \leq 0.05$ was considered significant.

Results and discussion

Based on the result obtained from 80 isolated samples, the frequency of Bacillus cereus strains from 
skin of hand was $16.25 \%$. Based on the result of SDSPAGE, from $13 \mathrm{~B}$. cereus strains isolated from skin of staff, $11(84.60 \%)$ strains have shown to be S-layer producers (Fig.1). Bacillus species have been the most bacterial separation from staff hand that shown in Fig. 2 (Jalalpoor et al., 2009a, b; Jalalpoor et al., 2010). Strains isolated from clinical samples could produce S-layer while the standard strains could not have produced S-layer (Kotiranta et al., 1998; Kotiranta et al., 1999). Considering similar studies in other countries, the frequency of Bacillus species in staff hand was $37 \%$ and frequency of Bacillus cereus strains on staff hand has been reported 15\% (Kamp \& Kramer, 2004; Vander Zwet et al., 2000).

Fig. 2. Frequency Nanostructure of S-Layer among the Bacillus cereus strains isolated from skin of staff

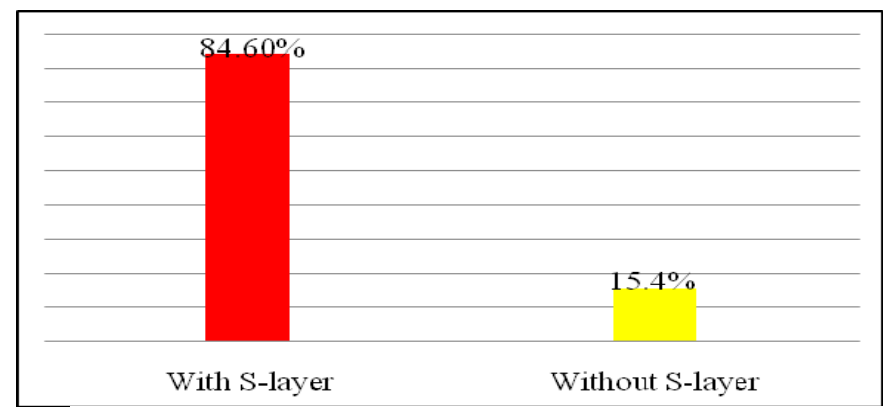

Based on the results obtained in the present study, (11) $84.60 \%$ of $B$. cereus strains isolated from staff hand have been the S-layer producer. The results of this study and other similar studies, treating many of S-layer in bacterial isolated from in vivo conditions, compared with bacterial isolated from in vitro conditions. S-layer structure is considered to offer pathogenic advantage to the bacteria, in this case thought that the Bacillus cereus strains, if considered on biological conditions, produces S-layer to protect from the influence of antibiotic and harmful enzymes in the human body (Jalalpoor et al., 2008;Jalalpoor et al., 2009a,b,c,d; Jalalpoor et al., 2010a).

Bacillus cereus strains resistant to antibiotics in hospitals, while in lack of bacterial population control, leads to rapid release of antibiotic resistant genes from resistant strains to sensitive strains and ultimately can lead to the spread of antibiotic resistant nosocomial infections in hospitals and in the community (Jalalpoor et al., 2010a,b).

Environmental surfaces carry the least risk of disease transmission and can be safely decontaminated using less rigorous methods than those used on medical instruments and devices. Isolation precautions are designed to prevent transmission of microorganisms by common routes in hospitals. Because agent and host factors are more difficult to control, interruption of transfer of microorganisms is directed primarily at transmission, approximately one third of nosocomial infections are preventable. Cleaning is the necessary first step of any sterilization or disinfection process. Cleaning is removing organic matter, salts, and visible soils, all of which interfere with microbial inactivation. Frequent hand washing is the single most important measure to reduce the risks of transmitting microorganisms from one person to another or from one site to another on the same patient. Although such hygienic practice is important to minimize the impact of this transfer, cleaning and disinfecting environmental surfaces is fundamental in reducing their potential contribution to the incidence of healthcare-associated infections (Rosenthal et al., 2009; Mielke et al., 2010; Rosenthal et al., 2010).

The present study as well as previous observations indicate high frequency of S-layer in Bacillus cereus strains isolated from in vivo condition. Improving the hygienic condition including hand clean and control of bacterial population in hospital environment, can lead to the actual control antibiotic resistance among bacterial population.

\section{Acknowledgments}

Author would like to thank the subspecialty Alzahra Hospital Management, Isfahan Uniersity, Management of science research lab of Isfahan University, journals manager of Isfahan University of Medical Sciences, Azzahra Hospital Infection control committees and all persons help us in concert to achieve this research.

\section{References}

1. Eichler I (2003) Facing extremes: archaeal surfacelayer (glyco) proteins. Microbiol. 149, 3347-3351.

2. Hilliard NJ, Schelonka RL and Waites KB (2003) Bacillus cereus bacteremia in a preterm neonate. $J$. Clin. Microbiol. 41, 3441-3444.

3. Jalalpoor S, Kasra Kermanshahi R, Noohi $A$ and Zarkesh Esfahani H (2007) Study of $\beta$-lactamase and S-layer Production in some of Isolated Pathogen Bacteria From Clinical and Environmental Hospital Samples. M.Sc. thesis, Iran, Tehran, Islamic Azad University Science and Research Branch Tehran, Iran.

4. Jalalpoor S, Kasra Kermanshahi R, Nouhi AS and Zarkesh Esfahani H (2009) Survey and Comparative Bacterial Spread Pattern in Staff Hands and High and Low Contact Hospital Surfaces. Third Iranian Congress of Clinical Microbiology, Shiraz, Iran.

5. Jalalpoor S, Kasra Kermanshahi R, Nouhi AS and Zarkesh Esfahani H (2009a) The comparative frequency the $\beta$-lactamase Production and antibiotic susceptibility pattern of bacterial stains isolated from Staff Hands and Hospital Surfaces in Azzahra Hospital-Isfahan. Iran J. Med. Microbiol. 3(4), 37-45.

6. Jalalpoor S, Kasra Kermanshahi R, Nouhi AS and Zarkesh Esfahani H (2009b) Antibiotic Resistance in B.cereus st. Isolated from Staff Hands and Hospital Surfaces. Third Iranian Congress of Clinical Microbiology, Shiraz, Iran.

7. Jalalpoor S, Kasra Kermanshahi R, Nouhi AS and Zarkesh Esfahani H (2010a) Survey Characterization 
Nano Structure Surface Layer in Some of Pathogen Bacteria. Zahedan J. Res. Med. Sci. 12(4): In Press.

8. Jalalpoor S, Kasra Kermanshahi R, Nouhi AS and Zarkesh Isfahani H (2009c) The Prevalence of Nanostructure Surface Layer in Bacillus cereus strains Isolated from Staff Hands and Hospital Surfaces. J. Isfahan Med. Sch. 27(100), 632-645.

9. Jalalpoor S, Kasra Kermanshahi R, Nouhi AS and Zarkesh Isfahani H (2009d) Survey effect of in-vivo and in-vitro condition on expression of surface layer genes in bacteria. J. Iran Chem. Soc. 6 (Suppl): S11.

10. Jalalpoor $S$, Kasra Kermanshahi R, Nouhi AS, Zarkesh Esfahani H and Mobasherizadeh S (2010b) Survey Prevalence and Resistance to Some Beta lactame Antibiotics in Bacillus cereus strains Isolated of AZZAHRA Hospital. Iran J. Biol. 23(4), 470-477.

11. Jalalpoor Sh, Kasra Kermanshahi R , Nouhi A.S , Zarkesh Esfahani H (2008) Study to Spreading Bacteria in How and Low Contact Surfaces in Hospital. 9th Iranian Congress of Microbiology, Iran, kerman.4-6 March.208.

12. Jalalpoor Sh,Kasra Kermanshahi R , Nouhi A.S , Zarkesh Esfahani H (2010) Survey Frequency of $\beta$ lactamase Enzyme and Antibiotic Sensitivity Pattern in Isolated Pathogen Bacteria from Low and High Hospital Contact Surfaces. Pajuhandeh J.15 (2), 7782.

13. Kamp G and Kramer A (2004) Epidemiologic Background of Hand Hygiene and Evaluation of the Most Important Agents for Scrubs and Rubs. Clin. Microbiol. Rev. 17(4), 863-93.

14. Kotiranta A, Haapasalo M and Kari K (1998) Surface Structure, Hydrophobicity, Phagocytosis, and Adherence to Matrix Proteins of Bacillus cereus Cells with and without the Crystalline Surface Protein Layer. Infect Immun. 66(10), 4895-4902.

15. Kotiranta AK, Hitoshi I, Markus P, Haapasalo P and Kari L (1999) Radiation sensitivity of Bacillus cereus with and without a crystalline surface protein layer. FEMS Microbiol. Lett.179, 275-280.

16. Masahiro Y, Hirofuji T, Motooka N, Nozoe K, Shigenaga K and Anan H (2003) Humoral Immune Responses to S-layer-Like Proteins of Bacteroides forsythus. Clin. Diagnost. Laborate. Immune. 10(3), 383-387.

17. resistance to antibiotics in Europe - Primum nonnocere Mesnage S, Haustant M and Foue A (2001) A general strategy for identification of S-layer genes in the Bacillus cereus group: molecular characterization of such a gene in Bacillus thuringiensis subsp. galleriae NRRL 4045.J Microb.147, 1343-1351.

18. Messner $P$, Steiner $K$, Zarschler $K$ and Schaffer $C$ (2008) S-layer nanoglycobiology of bacteria. Carbohydr. Res. 343(12), 1934-1951.

19. Mielke M (2010) Prevention and control of nosocomial infections and: elements of successful
Vol. 5 No.S3 (Mar 2012) ISSN: 0974-6846

prevention and control of healthcare-associated infections. Int. J. Med. Microbiol. 300(6), 346-50.

20. Rosenthal VD, Maki DG and Jamulitrat S (2010) International Nosocomial Infection Control Consortium (INICC) report, data summary for 20032008. Am. J. Infect. Control. 38(2), 95-104.

21. Rosenthal VD, Maki G and Jamulitrat DS (2010) International Nosocomial Infection Control Consortium (INICC) report, data summary for 20032008, issued June 2009. Am. J. Infect. Control, 38, 95-106.

22. Sambrook J and Russell DW (2001) Molecular Cloning: A Laboratory Manual, 3rd Edition. Cold Spring Harbor, NY: Cold Spring Harbor Laboratory Press.

23. Sara M (2001) Conserved anchoring mechanisms between crystalline cell surface S-layer proteins and secondary cell wall polymers in Gram-positive bacteria. Trends Microbiol. 9, 47-9.

24. Sara M and Sleytr UB (2000) S-layer Proteins. J. Bacteriol. 182(4), 859-68.

25. Schaffer C and Messner P (2001) Glycobiology of surface layer proteins. Biochimie. 83, 591-99.

26. Schaffer C and Paul M (2005) The structure of secondary cell wall polymers: how Gram-positive bacteria stick their cell walls together. Microbiol. 15, 643-651.

27. Sehulster L and Raymond YW (2003) Guidelines for Environmental Infection Control in Health-Care Facilities. U.S. Department of Health and Human Services Centers for Disease Control and Prevention (CDC). Atlanta GA 30333.

28. Todor k (2005) Bacterial Structural in Relationship to Pathogenicity, available at www.Texbook of Bacteriology.net.

29. Vander Zwet WC, Parlevliet GA, Savelkoul PH, Stoof J,Kaiser AM (2000) Outbreak of Bacillus cereus infection in a neonatal intensive care unit traced to balloons used in manual ventilation. J. Clin. Microbiol .38, 4131-6.

30. Washington C, Stephen A, Janda W, Koneman E, Procop G, Schreckenberger P and Woods G (2006) Koneman's Color Atlas and Textbook of Diagnostic Microbiology, Sixth edition.USA: Lippincott wiliams \& wilkins, pp:775-779. 